\title{
PREPARATION AND CHARACTERIZATION OF ELECTROLESS Ni COATED NANO ALUMINA POWDER UNDER DIFFERENT SENSITIZATION - ACTIVATION CONDITIONS
}

\author{
Sameer Kumar $D^{1 *}$, Naga Sai Suman $K^{2}$, Kalyana Krishna $Y^{3}$ \\ ${ }^{1}$ Department of Mechanical Engineering, Bapatla Engineering College, Bapatla, India \\ ${ }^{2}$ Department of Mechanical Engineering, Andhra University College of Engineering, \\ Visakhapatnam, India \\ ${ }^{3}$ Department of Mechanical Engineering, QIS College of Engineering \& Technology, \\ Ongole, India
}

Received 27.12.2019

Accepted 26.05.2020

\begin{abstract}
The development of electroless coatings on various substrates has gained much interest among researchers for the sake of improved properties. However, the coating on ceramic particles as a source of reinforcement is still a challenge for the researchers and requires a good comprehension of fundamentals since the coating thickness relies upon many parameters. Particularly the sensitization and activation conditions are more important for the creation of an ideal environment to draw metallic ions as a coating layer. Therefore, this paper examines the role of sensitization and activation conditions on the viability of nickel coating on the alumina particles of an average size of $50 \mathrm{~nm}$. A comparison is made between two environments, namely individual and blended activations in the preparation of coated particles. Characterization studies are also presented to support the discussion.
\end{abstract}

Keywords: electroless plating; $\mathrm{Ni}$ coating; sensitization; activation; $\mathrm{Al}_{2} \mathrm{O}_{3}$ powder; ceramics; surface preparation. 


\section{Introduction}

Composites are one of the key areas of research and grown in an exponential way as these materials possess lightweight and high strength in economic applications. Particularly, Metal Matrix composites (MMCs) have made a great impact in replacing the conventional monolithic materials. Alumina is the most commonly used material in modern MMCs as a source of reinforcement, given its desirable characteristics [1-3]. However, the preparation of a composite material needs special attention in achieving (i) low porosity (ii) uniform distribution (iii) wettability and (iv) matrix - reinforcement interactions for the enhanced properties [4]. Some of the issues mentioned above were solved by changing the process parameters; however, the interactions play a significant role in deciding the performance of the composite. To promote enhanced interactions between matrix and reinforcement, coating the ceramic particulates with metal is found to be one of the prominent methods in recent times [4-9].

In general, a metallic coating can be done by using Electroless plating [5], Sol-Gel method [10], Heterogeneous Precipitation [11], and ball milling [12] etc., but Electroless plating has been identified as one of the effective techniques in view of simplicity and unique properties. Nickel and copper plating are the most commonly used electroless plating materials for industrial applications, while an electroless nickel coating gives particularly great hardness, fatigue strength, protection from wear and corrosion with a uniform covering over a wide scope of base materials [13].

The electroless plating process has two steps viz. surface preparation and bathing. This process consists of many parameters that directly affect the coating thickness [1418]. Leon et al. [5] described the electroless nickel deposition process on micro-level SiC and $\mathrm{Al}_{2} \mathrm{O}_{3}$ particles and observed continuous nickel films on both the particles. Mehmet Uysal [6] discussed the influence of chemical quantities and powder concentration on the preparation core-shell $\mathrm{Al}_{2} \mathrm{O}_{3} / \mathrm{Ni}$ powders and further added that maintenance or control of these process parameters is essential for effective plating. Pang et al. [14] and Sameer et al. [19] emphasized the importance of sensitization and activation to attract the metallic ions on nano-ceramic particles. A two-step method of sensitization and activation is the most widely used methodology for surface preparation, while the one-step activation technique is becoming popular in the recent years as this process is quite simple with an economic advantage [20].

Therefore, this work confers to examine the effectiveness of coating achieved by both two-step and one-step activation methods on nano-sized $\mathrm{Al}_{2} \mathrm{O}_{3}$ powders prepared through standard nickel electroless plating procedures. The mechanism, experimental conditions, and the influence of these conditions on coating are elaborated in the later sections along with the characterization studies conducted.

\section{Experimental}

\section{Raw Materials}

$99 \%$ pure $\mathrm{Al}_{2} \mathrm{O}_{3}$ powders of average particle size $50 \mathrm{~nm}$, supplied by $\mathrm{M} / \mathrm{s}$ United Nano Tech Products Limited (UNTPL), Howrah, were used in this experiment. 


\section{Principle}

The basic mechanism of electroless plating procedure involves the reduction of a metallic ion in an aqueous solution containing a reducing agent along with accelerators. This metal ion is attracted to the nucleation sites created on the surface of the substrate via the pre-treatment process [18]. Sensitization and activation procedures make the conditions favorable for plating. When the activated $\mathrm{Al}_{2} \mathrm{O}_{3}$ powders are added to the bath, the metallic nickel could be deposited with the following redox reactions. The detailed stoichiometric reactions are mentioned through Equations 1-3, while the mechanism for the plating process is shown in Figure 1.

$$
\begin{aligned}
& \mathrm{Sn}^{2+}+\mathrm{Pd}^{2+} \rightarrow \mathrm{Sn}^{4+}+\mathrm{Pd}^{0} \\
& \mathrm{Ni}^{2+}+\mathrm{H}_{2} \mathrm{PO}_{2}^{-}+\mathrm{H}_{2} \mathrm{O} \rightarrow \mathrm{H}_{2} \mathrm{PO}_{3}^{-}+\mathrm{H}_{2}+\mathrm{Ni}^{0} \\
& \mathrm{Pd}+\mathrm{Ni}^{2+} \rightarrow \mathrm{Pd}^{2+}+\mathrm{Ni}
\end{aligned}
$$

\section{Experimental Procedure}

The chemicals and process parameters used in the pre-treatment process are mentioned in Table 1. Ultrasonic cleaning of particles was done after each step for better nucleation [21]. After pre-treatment, particles were dried and forwarded to the electroless nickel deposition bath. The chemicals used, their functional significance alongside their corresponding quantities were given in Table 2 . The alkaline bath was considered in the present investigation as these produce low phosphorous content [20,21].

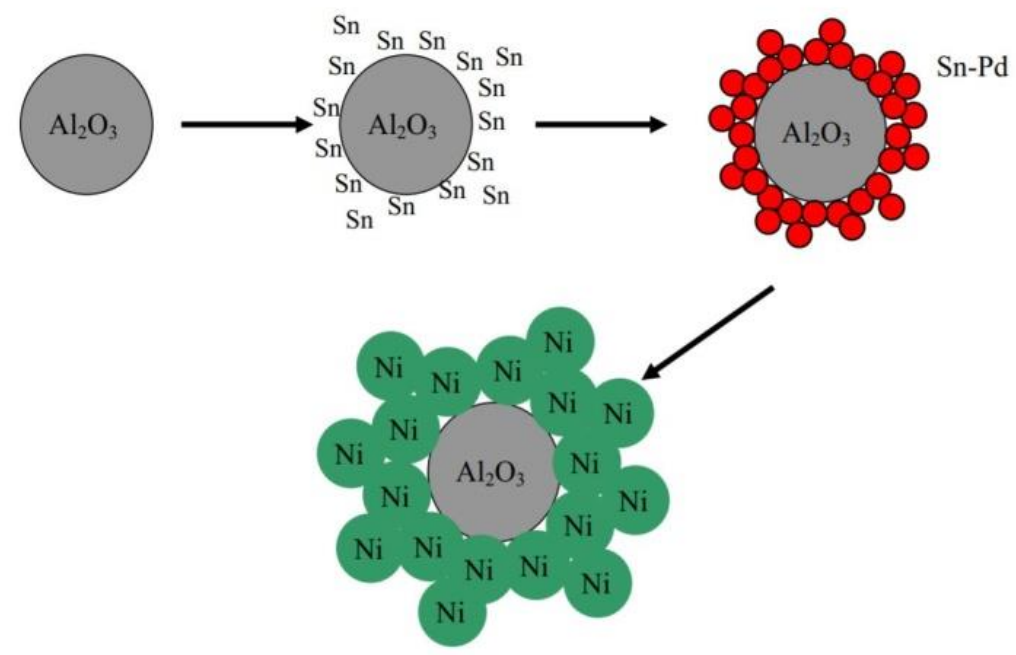

Fig. 1. Electroless Ni plating process with $\mathrm{SnCl}_{2}$ sensitization and $\mathrm{PdCl}_{2}$ activation [14]. 
Table 1. Pre-treatment Process.

\begin{tabular}{|c|c|c|c|}
\hline Process & Chemicals & Concentration & Time \\
\hline Ultra-Sonic Cleaning & Acetone & & $20 \mathrm{~min}$ \\
\hline Etching & $\mathrm{HNO}_{3}$ & $10 \mathrm{ml} / \mathrm{L}$ & $15 \mathrm{~min}$ \\
\hline Rinsing & Distilled Water & & $10 \mathrm{~min}$ \\
\hline \multicolumn{4}{|c|}{ Two-Step Activation Procedure [19] } \\
\hline \multirow{2}{*}{ Sensitization } & $\mathrm{Sncl}_{2} .6 \mathrm{H}_{2} \mathrm{O}$ & $10 \mathrm{gm} / \mathrm{L}$ & \\
\hline & $\mathrm{HCL}$ & $30 \mathrm{ml} / \mathrm{L}$ & $15 \mathrm{~min}$ \\
\hline Rinsing & Distilled Water & & $10 \mathrm{~min}$ \\
\hline \multirow{2}{*}{ Activation } & $\mathrm{PdCl}_{2}$ & $0.25 \mathrm{gm} / \mathrm{L}$ & \\
\hline & $\mathrm{HCl}$ & $3 \mathrm{ml} / \mathrm{L}$ & $15 \mathrm{~min}$ \\
\hline Rinsing & Distilled Water & & $10 \mathrm{~min}$ \\
\hline \multicolumn{4}{|c|}{ Single-Step / One - Step Activation Procedure [20] } \\
\hline \multirow{3}{*}{$\begin{array}{l}\text { Sensitization and } \\
\text { Activation }\end{array}$} & $\mathrm{SnCl}_{2} .6 \mathrm{H}_{2} \mathrm{O}$ & $2 \mathrm{gm} / \mathrm{L}$ & \\
\hline & $\mathrm{PdCl}_{2}$ & $0.2 \mathrm{gm} / \mathrm{L}$ & $15 \mathrm{~min}$ \\
\hline & $\mathrm{HCl}$ & $10 \mathrm{ml}$ & \\
\hline Rinsing & Distilled Water & & $10 \mathrm{~min}$ \\
\hline
\end{tabular}

Table 2. Composition and Conditions of the Bath [19].

\begin{tabular}{|c|c|c|}
\hline Chemicals and Conditions & Concentration & Purpose \\
\hline $\begin{array}{l}\text { Nickel chloride hexahydrate } \\
\left(\mathrm{NiCl}_{2} \cdot 6 \mathrm{H}_{2} \mathrm{O}\right)\end{array}$ & $30 \mathrm{gm} / \mathrm{L}$ & Source of Nickel ions \\
\hline $\begin{array}{l}\text { Sodium hypophosphite Mono Hydrate } \\
\left(\mathrm{NaH}_{2} \mathrm{PO}_{2} \cdot \mathrm{H}_{2} \mathrm{O}\right)\end{array}$ & $25 \mathrm{gm} / \mathrm{L}$ & Reducing agent \\
\hline Ammonium Chloride $\left(\mathrm{NH}_{4} \mathrm{Cl}\right)$ & $50 \mathrm{gm} / \mathrm{L}$ & Accelerator \\
\hline Tri Sodium Citrate $\left(\mathrm{Na}_{3} \mathrm{C}_{6} \mathrm{H}_{5} \mathrm{O}_{7} .2 \mathrm{H}_{2} \mathrm{O}\right)$ & $40 \mathrm{gm} / \mathrm{L}$ & Complexing agent \\
\hline Sodium Hydroxide $(\mathrm{NaOH})$ & Sufficient - & $\begin{array}{l}\text { To maintain the } \\
\text { required } \mathrm{pH}\end{array}$ \\
\hline $\mathrm{Al}_{2} \mathrm{O}_{3}$ Powder & $15 \mathrm{gm} / \mathrm{L}$ & \\
\hline Stirring Mode & Magnetic stirring & \\
\hline Bath Temperature & $85 \pm 2{ }^{\circ} \mathrm{C}$ & \\
\hline $\mathrm{pH}$ & 8 & \\
\hline Time & $20 \mathrm{~min}$ & \\
\hline
\end{tabular}

\section{Effect of Sensitization Conditions}

To study the impact of sensitization and activation conditions, two conditions we investigated in the present study. The first, after proper cleaning of the surface, the sample of $\mathrm{Al}_{2} \mathrm{O}_{3}$ powder underwent sensitization for $\mathrm{SnCl}_{2}$ and later activation for $\mathrm{PdCl}_{2}$ (Sample B). While the second condition, the single-step activation method, a combined solution of $\mathrm{SnCl}_{2}$ and $\mathrm{PdCl}_{2}$, was prepared for pre-treatment (Sample C). The samples were designated as given in Table 3 . 
Table 3. Sensitization and Activation Conditions.

\begin{tabular}{ll}
\hline Samples Designation & Condition \\
\hline A & ${\mathrm{Pure} \mathrm{Al}_{2} \mathrm{O}_{3} \text { powder }}$ \\
$\mathrm{SnCl}$ & sensitization first then $\mathrm{PdCl}_{2}$ activation \\
B & (Two-step activation method) \\
& Combined $\mathrm{SnCl}_{2}, \mathrm{PdCl}_{2}$ for sensitization and activation \\
C & (One-step activation method) \\
\hline
\end{tabular}

Characterization of Powders

The surface morphology of $\mathrm{Al}_{2} \mathrm{O}_{3}$ powders before and after electroless $\mathrm{Ni}$ deposition was characterized with the support of the FE Scanning Electron Microscope equipped with an energy dispersive spectroscopy (SIGMA HV - Carl Zeiss with Bruker Quantax 200 - Z10 EDS Detector). The Transmission Electron Microscopical (JEOL/JEM 2100) studies were carried out at Sophisticated Test \& Instrumentation Centre, CUSAT Campus, Cochin, INDIA.

\section{Results and discussion}

The density of all the samples was measured using the Archimedean principle and indicated in Figure 2. The density of Sample A is $3.90 \mathrm{~g} / \mathrm{cm}^{3}$, while the densities of Sample B and Sample C are $4.15 \mathrm{~g} / \mathrm{cm}^{3}$ and $4.09 \mathrm{~g} / \mathrm{cm}^{3}$, respectively. In both cases, Sample B and Sample C have increased density compared to Sample A. This increase in density may be attributed due to the addition of metallic Ni on the surface of Alumina ceramic $[4,5,14,19]$.

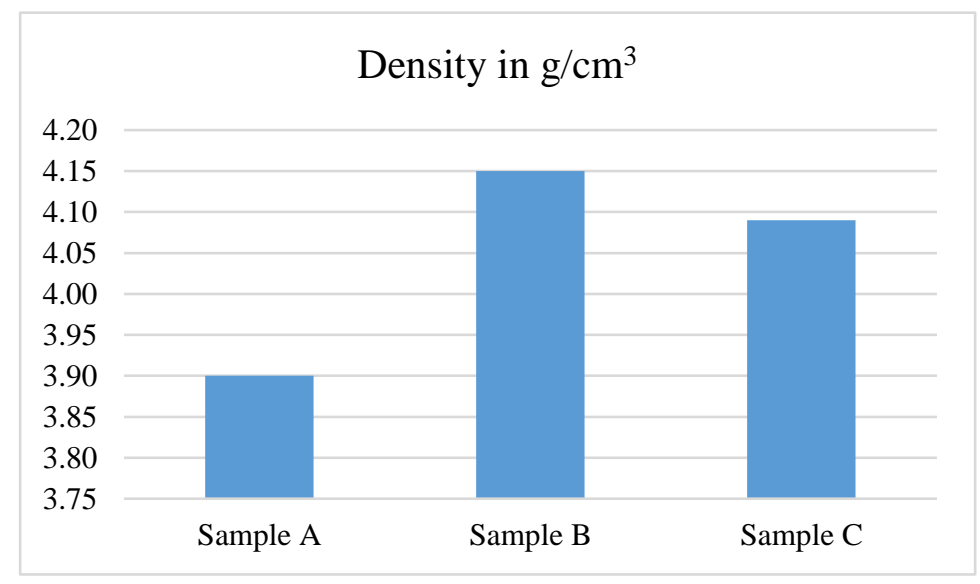

Fig. 2. Densities of Samples A, B and C.

The XRD patterns of samples were shown in Figure 3. Figure 3(a) has the diffraction peaks of $\mathrm{Al}_{2} \mathrm{O}_{3}$ (Sample A) while Figure. 3 (b) and 3(c) contain the diffraction peaks of $\mathrm{Ni}$ coated $\mathrm{Al}_{2} \mathrm{O}_{3}$ (Sample $\mathrm{B}$ and $\mathrm{C}$ ). It was observed that the diffraction peaks in Sample B and C were broad when compared with Sample A, and a shoulder has been 
observed in the diffraction peaks at 2-Theta angle 40-50. Based on the JCPDS data, the Nickel peaks have been observed at angle $44^{\circ}$.

Furthermore, it has been reported in the literature that the wider peak gives preliminary information of more coating thickness with a small crystal size $[14,19]$. Therefore, Sample B seems to have more deposition of metallic Nickel around the alumina (Figure 3 (b)). Thus, the XRD analysis also indicates the presence of Ni and $\mathrm{Al}_{2} \mathrm{O}_{3}$ in the prepared powders along with preliminary results.

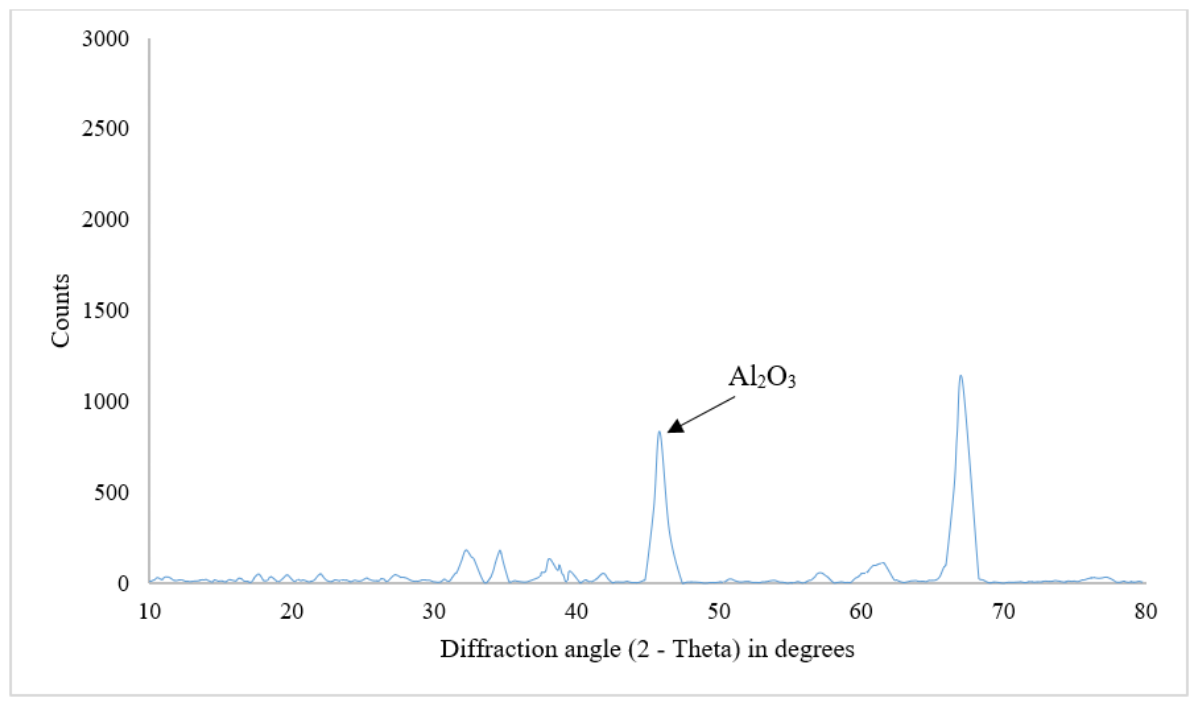

Sample A

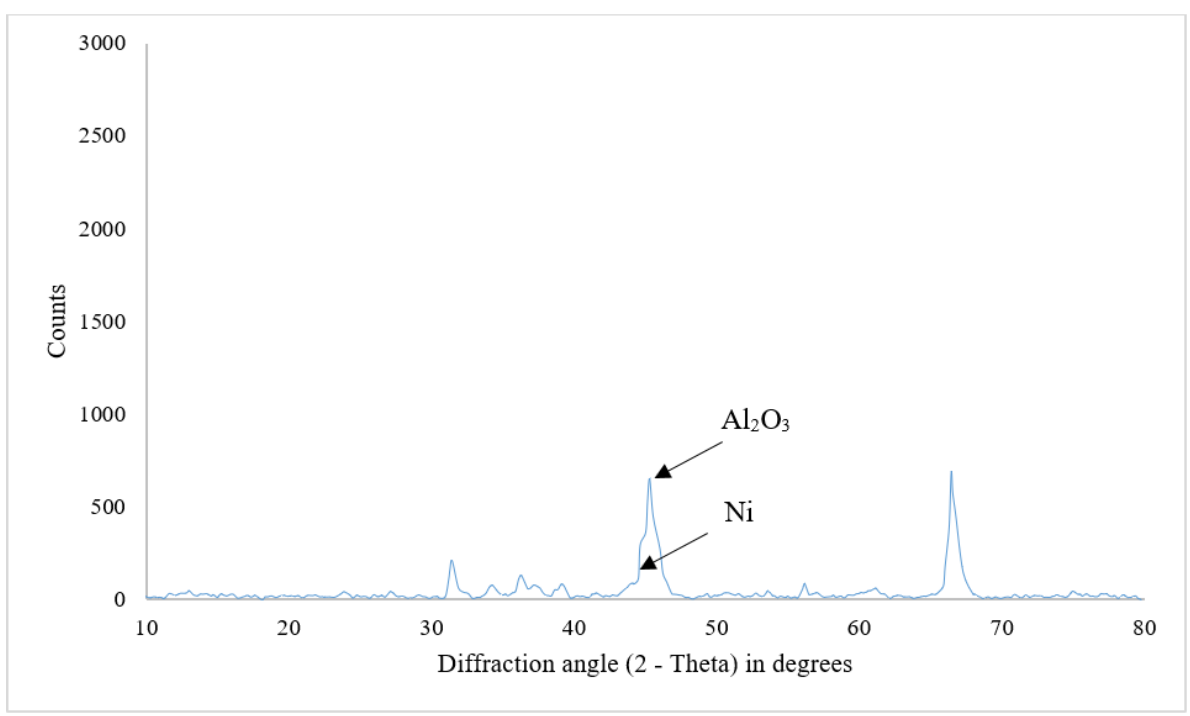

Sample B 


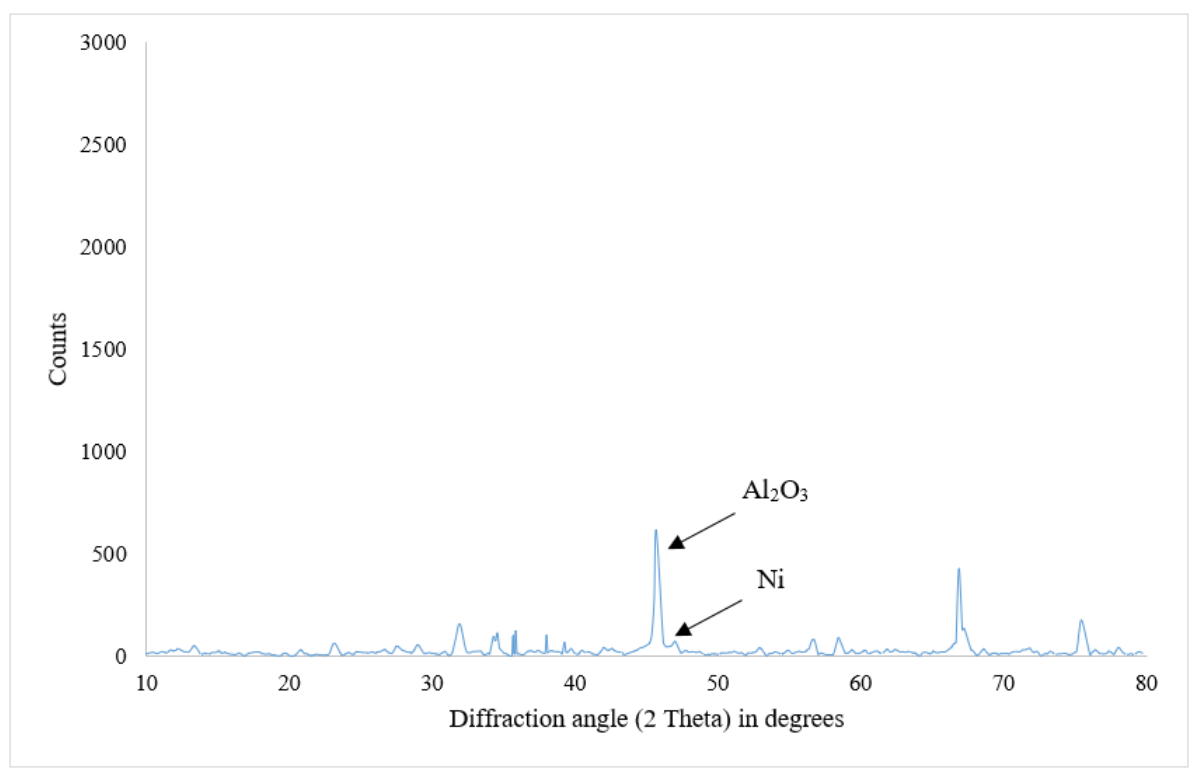

\section{Sample $C$}

Fig. 3. XRD Patterns of samples $A, B$, and $C$.

Figure 4 illustrates the FESEM images of nano-sized $\mathrm{Al}_{2} \mathrm{O}_{3}$ powders before and after electroless deposition with different sensitization and activation conditions. It has been observed that the surface of pure alumina (Sample A) was very plain (Figure 4(a)), while a coating has been observed on the particles was seen in Sample B and Sample C (Figure 4 (b) and (c)).

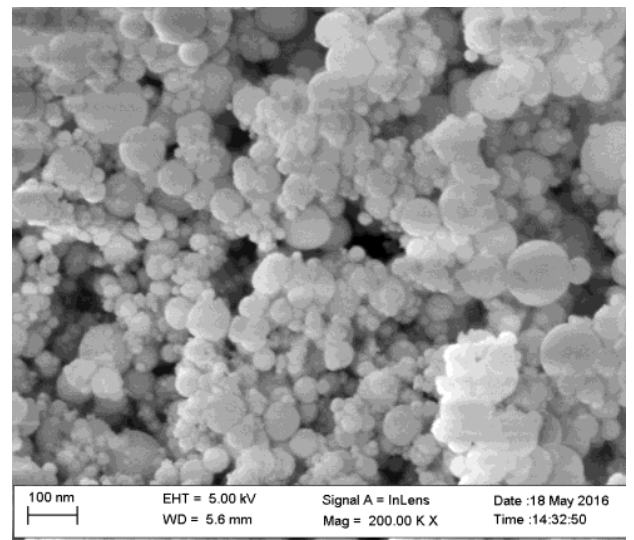

(a) Sample A

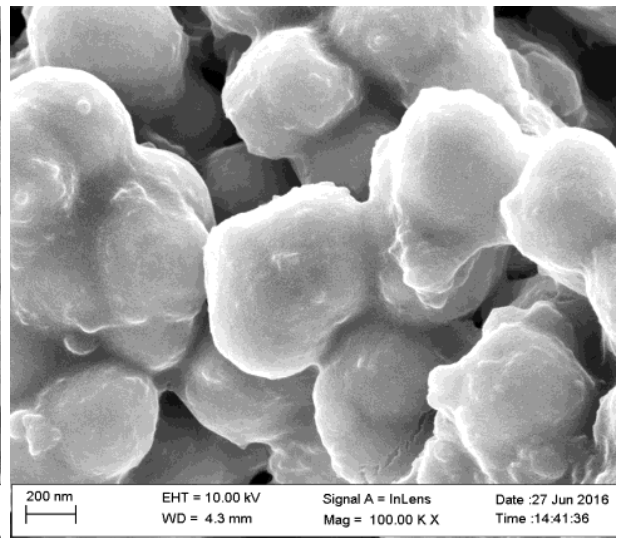

(b) Sample B 


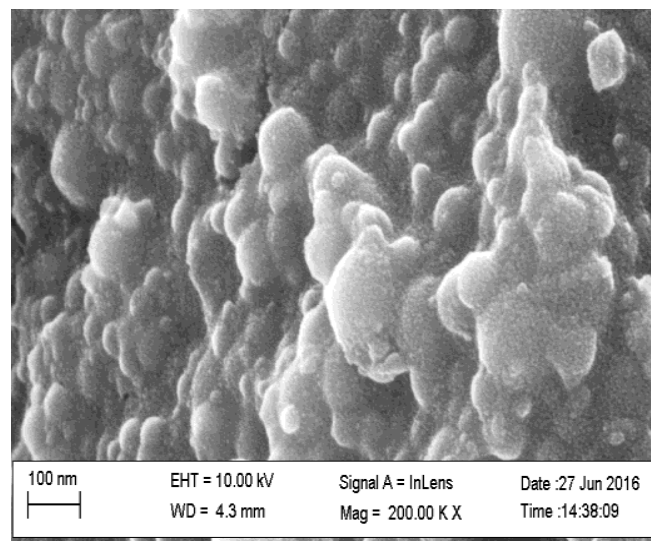

(c) Sample C

Fig. 4. FESEM Analysis of Samples.

From Figure 5, the traces of $\mathrm{Ni}, \mathrm{P}, \mathrm{O}$, and $\mathrm{Al}$ were observed in the EDS analysis of Samples B and C as an indication of Ni-P coating. Both samples exhibited similar kinds of results in the characterization studies [ Figure 5 (a) and (b)]. The combination of Nickel - Phosphorous content is appeared because of the reducing agent used in the study [6,2224]. The studies are further carried towards coating thickness and crystallinity in assessing the quality of coated particles.

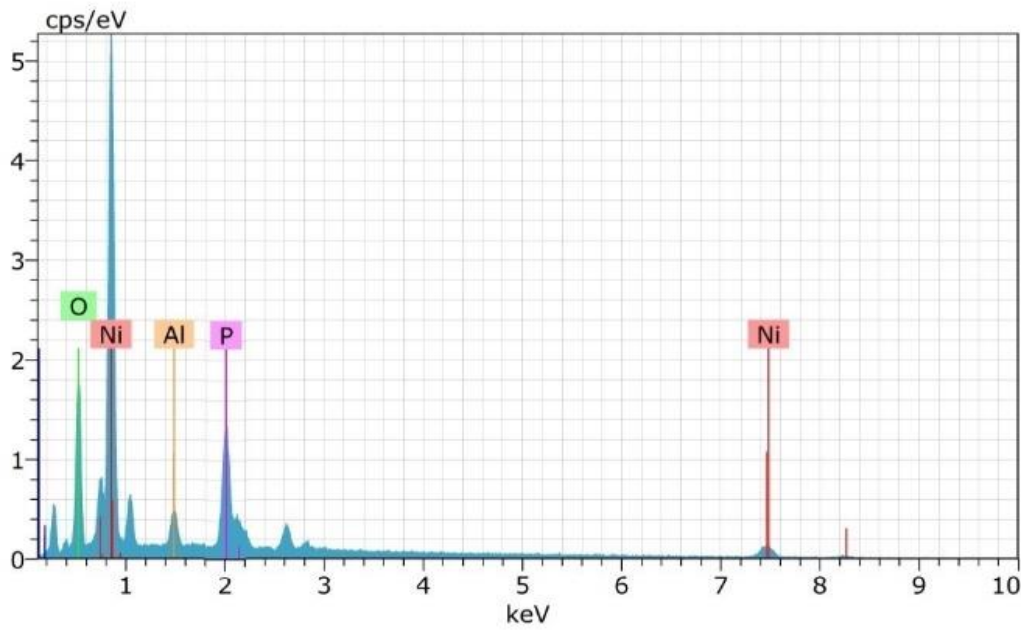

(a) Sample B 


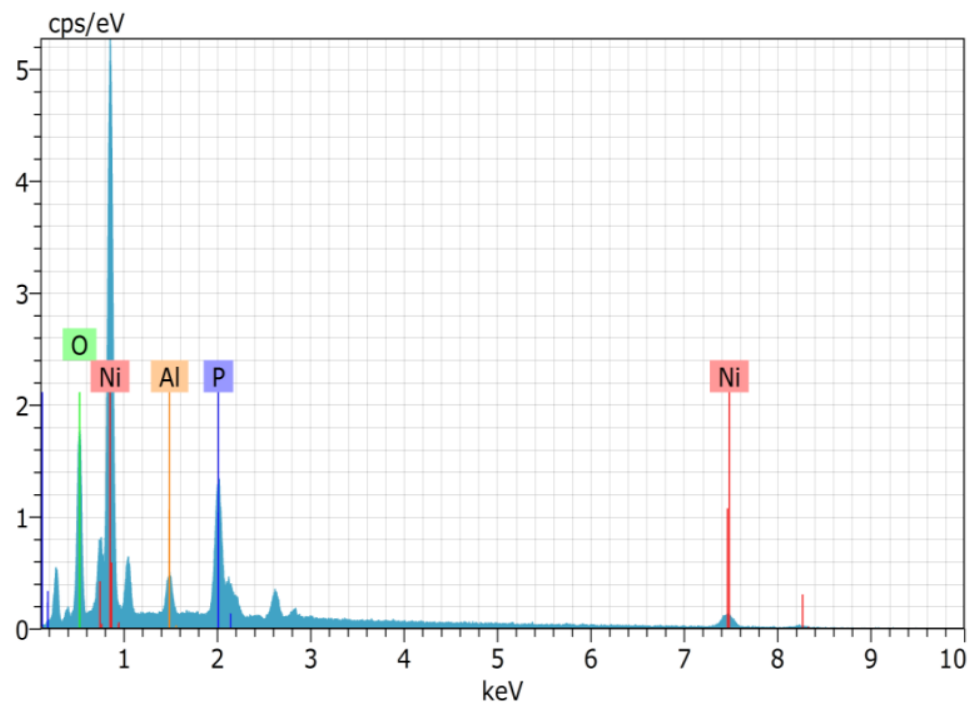

(b) Sample C

Fig. 5. EDS Analysis.

The TEM images of powder of Samples A, B, and C were shown in Figure 6. The surface of pure Alumina particle, Sample A, was round (Figure 6 (a)), while the surfaces of samples B and C have a clear indication of a coating. Sensitization and activation conditions helped the particles to attract Nickel; hence the coating was observed in both the samples B and Sample C. The two-step method of sensitization and activation provided a good platform for the $\mathrm{Ni}$ deposition over the nano $\mathrm{Al}_{2} \mathrm{O}_{3}$ surface and is confirmed in accordance with FESEM results along with EDS. The coating thickness was more uniform and varied between $2 \mathrm{~nm}$ to $31 \mathrm{~nm}$ of the particle in the case of Sample B (Figure 6 (b). The two-step method helps to create more nucleation sites as such, the sensitization and activation are done in separate baths. The pores on the surface are activated after the complete sensitization of the surface. The deposition process begins at random sites and keeps on developing to cover the full particle over time as a core shelllike structure [15]. The coating in Sample C does not have uniform coating like Sample B. For sample $C$, Metal island type distribution was observed as because of the single step activation method (Figure 6 (c)). M. Schlesinger reported that the single-step activation leads to low coating thickness over the particles [20], as confirmed by the present study. The quantity of $\mathrm{Sn}^{+2}$ was not sufficient to create more nucleation sites to produce a uniform coating. 


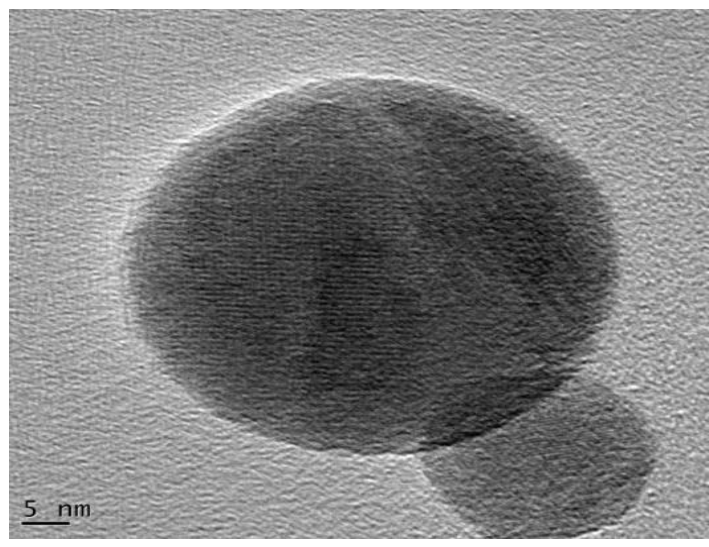

(a) Sample A

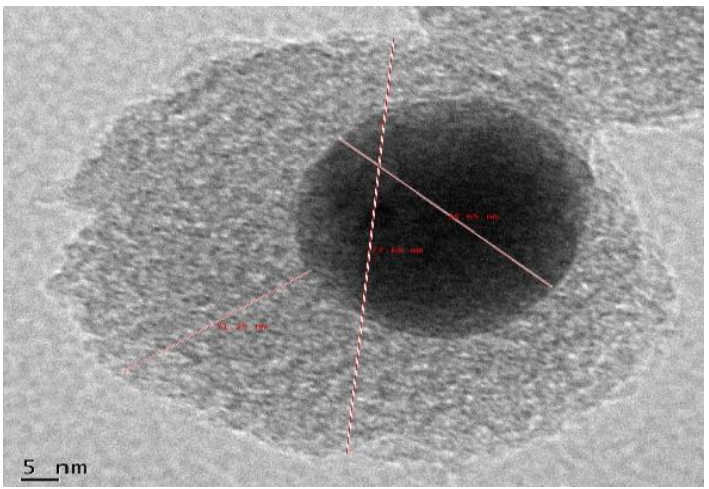

(b) Sample B

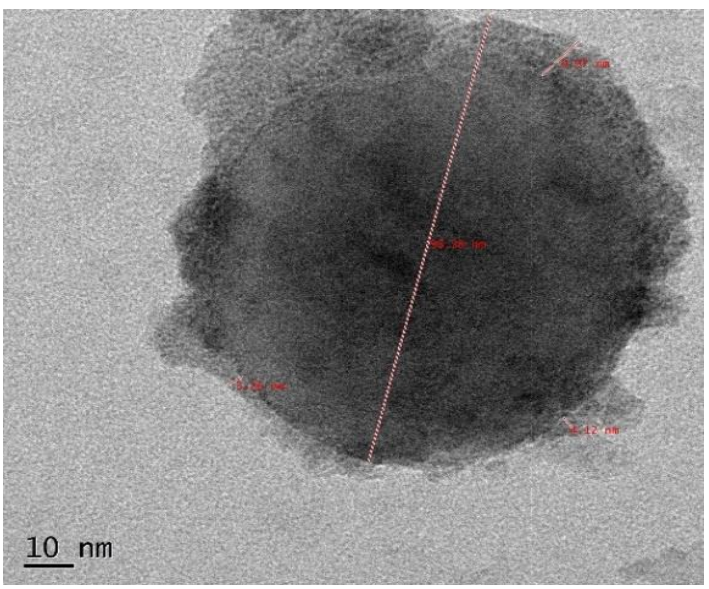

(c) Sample C

Fig. 6. TEM Images of Sample A, B, and C. 


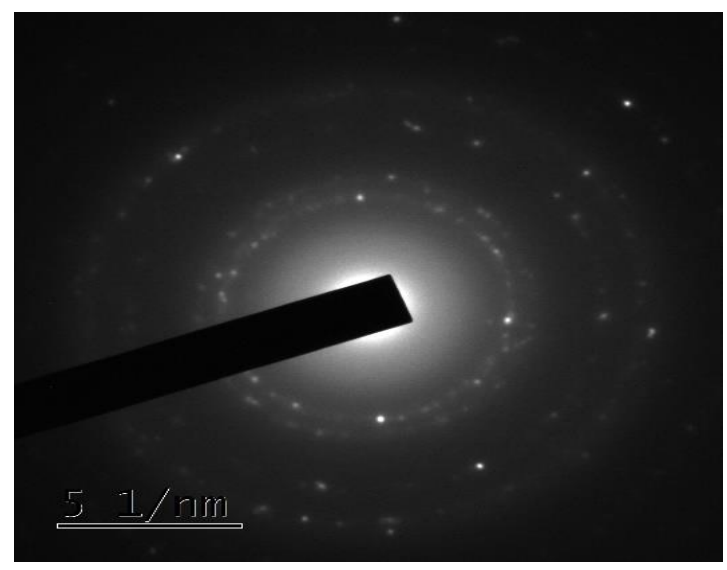

(a) Sample B

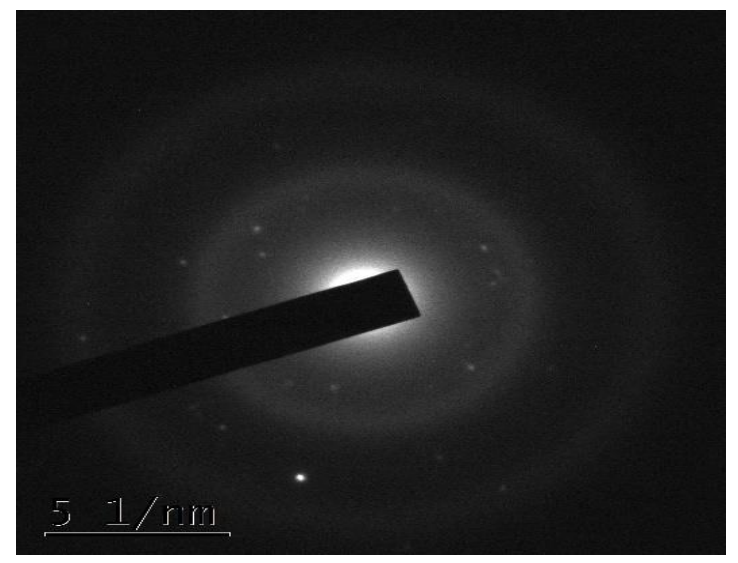

Sample $C$

Fig. 7. Selective Area Diffraction (SAD) images of Sample B and C.

The SAD patterns for Sample B and C were shown in Figure 7. The structure of $\mathrm{Ni}$ coated Nano $\mathrm{Al}_{2} \mathrm{O}_{3}$ powder was crystalline in the case of sample B (Figure 7 (a) ), and it is a mixture of orderly with the disorderly crystalline grains in Sample C when speculated from Selective diffraction image ( Figure 7 (b)). From the results, it is observed that the pre-treatment and the surface roughness significantly promoted the uniform deposition of Nickel on the alumina surface. The mode of individual activation step is to be superior in the formation of catalytic sites for the nucleation process, and a high surface roughness produced by full sensitization favoured a lateral growth mechanism of the Ni$\mathrm{P}$ deposit and to form a core-shell structure. 


\section{Conclusions}

From the present work, the following conclusions are drawn:

- This paper highlighted the importance of proper sensitization and activation conditions in achieving the surface-modified ceramics for the sake of improved properties.

- The color change and density values have given the preliminary indications of coating while the results of XRD, FESEM, and TEM are analyzed and presented to observe the effectiveness of coating on ultrafine ceramic particles.

- The two-step method or individual method of sensitization and activation conditions lead to the preparation of core-shell type Ni coated nano-sized $\mathrm{Al}_{2} \mathrm{O}_{3}$ powders while one step method produced island type structure.

- Palladium (Pd) nuclei on substrate surfaces created more catalytically active sites to initiate the electroless plating process in the two-step plating process. In case of mixed $\mathrm{PdCl}_{2} / \mathrm{SnCl}_{2}$ catalyst solution, the active sites consisting of both Pd-Sn alloy had a lower number of catalytic sites that resulted in a less effective attraction of metallic Nickel.

- Both the two-step and the single-step sensitization and activation methods produced nickel coating on the nano alumina particles. However, the twostep method appeared to be desirable for more coating thickness, while the one-step method is simple and fast, but with a lower coating thickness than the two-step method. 


\section{References}

[1] D. J. Lloyd: International Materials Reviews, 39 (1994) 1-23.

[2] M.A. Eltaher, A. Wagih, A. Melaibari, A. Fathy, G. Lubineau: Ceramics International, 46 (2020) 5779-5787.

[3] A.M. Sadoun, A. Fathy: Ceramics International, 45 (2019) 24784-24792.

[4] R. Taher Zadeh Mousa Vian et al.: Int J Adv Manufacturing Technol, 81 (2015) 433-444.

[5] C. A. Leon, R. A. L. Drew: Journal of Materials Science, 35 (2000) 4763 - 4768.

[6] Mehmet Uysal et al.: Ceramics International, 39 (2013) 5485-5493.

[7] Sameer Kumar D, K.N.S. Suman, Palash Poddar: Material Research Express, 4 (2017) 066505.

[8] Sameer Kumar Devarakonda, Naga Sai SumanKoka: Journal of The Institution of Engineers (India): Series D, 99 (2018) 201-208.

[9] A. Fathy, A. Abu-Oqail, A. Wagih: Ceramics International, 44 (2018) 2213522145.

[10] Guo-jun Li, Xiao-xian Huang, Jing-kun Guo: Materials Research Bulletin, 36 (2001) 1307-1315.

[11] M. V. S. Babu, K. N. S. Suman, A. Rama Krishna: Journal of Mechanical Engineering Research and Developments, 40 (2017) 35-41.

[12] Cristina Voicu et al.: Solid State Phenomena, 216 (2014) 146-150.

[13] Glenn O. Mallory, Juan B. Hajdu: Electroless Plating: Fundamentals and Applications. Reprint Edition, Sponsored and published by American Electroplaters and Surface Finishers Society, Cambridge University Press, (1990).

[14] J.N.Pang, et al: Ceramics International, 42 (2016) 4491-4497.

[15] Ron Parkinson: Properties and applications of electroless nickel. Nickel Development Institute. Information from

[16] https://www.nickelinstitute.org/media/1769/propertiesandapplicationsofelectrole ssnickel_10081_.pdf Accessed 3 Jun 2020.

[17] C.T.J. Low, R.G.A. Wills, F.C. Walsh: Surf Coat Technol, 201 (2006) 371-383.

[18] C. A. Loto: Silicon, 8 (2016) 177-186.

[19] Jerin K. Pancrecious, Sarah Bill Ulaeto, R. Ramya, T. P. D. Rajan and B. C.: International Materials Reviews, 63 (2018) 488-512.

[20] D. Sameer Kumar, K.N.S. Suman, P. Rohini Kumar: International Journal of Advanced Science and Technology (IJAST), 97 (2016) 59-68.

[21] Mordechay Schlesinger: Electroless Deposition of Nickel. Chapter 18 in Modern Electroplating, Fifth Edition, John Wiley \& Sons, (2010).

[22] X. Xu, Z. D. Cui, S. L. Zhu, Y. Q. Liang, X. J. Yang: Surface Coating Technology, 240 (2014) 425-431.

[23] K. Hari Krishnan et al.: Metallurgical and Materials Transactions A, 37 (2006) 1917-1926.

[24] Jothi Sudagar, Jianshe Lian, Wei Sha: Journal of Alloys and Compounds, 571 (2013) 183-204.

[25] S. Karthikeyan, L. Vijayaraghavan: International Journal of Engineering Research \& Technology (IJERT), Special Issue - NCRAIME-2015 Conference Proceedings, Volume 3. Issue 26, (2015) 1-4 ISSN: 2278-0181.

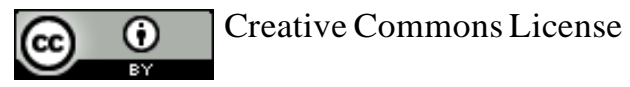

This work is licensed under a Creative Commons Attribution 4.0 International License. 